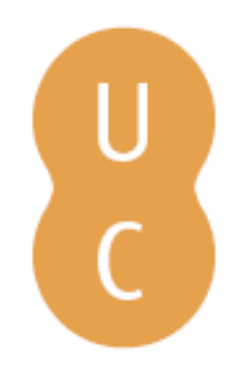

\title{
nombalina
}

\section{Percursos pedestres e turismo de passeio pedestre em Portugal}

Autor(es): $\quad$ Tovar, Zília; Carvalho, Paulo

Publicado por: Imprensa da Universidade de Coimbra

URL persistente:

URI:http://hdl.handle.net/10316.2/37375

DOI:

DOI:http://dx.doi.org/10.14195/978-989-26-0754-2_15

Accessed : $\quad$ 26-Apr-2023 13:02:57

A navegação consulta e descarregamento dos títulos inseridos nas Bibliotecas Digitais UC Digitalis, UC Pombalina e UC Impactum, pressupõem a aceitação plena e sem reservas dos Termos e Condições de Uso destas Bibliotecas Digitais, disponíveis em https://digitalis.uc.pt/pt-pt/termos.

Conforme exposto nos referidos Termos e Condições de Uso, o descarregamento de títulos de acesso restrito requer uma licença válida de autorização devendo o utilizador aceder ao(s) documento(s) a partir de um endereço de IP da instituição detentora da supramencionada licença.

Ao utilizador é apenas permitido o descarregamento para uso pessoal, pelo que o emprego do(s) título(s) descarregado(s) para outro fim, designadamente comercial, carece de autorização do respetivo autor ou editor da obra.

Na medida em que todas as obras da UC Digitalis se encontram protegidas pelo Código do Direito de Autor e Direitos Conexos e demais legislação aplicável, toda a cópia, parcial ou total, deste documento, nos casos em que é legalmente admitida, deverá conter ou fazer-se acompanhar por este aviso. 


\title{
ZÍLIA TOVAR
}

Câmara Municipal de Montemor-o-Novo

ztovar@gmail.com

\section{PAULO CARVALHO}

CEGOT, Universidade de Coimbra

paulo.carvalho@fl.uc.pt

\author{
PERCURSOS PEDESTRES E TURISMO \\ DE PASSEIO PEDESTRE EM PORTUGAL
}

\section{Introdução}

A prática de andar a pé em trilhos sinalizados (pedestrianismo) é uma atividade muito popular e com elevadas perspetivas de crescimento. Trata-se de uma atividade de baixo custo para o praticante e pouco exigente em termos de forma física, associada a um estilo de vida saudável. Embora seja praticado em qualquer tipo de meio, é com os espaços naturais que o pedestrianismo tem maior relação.

Para facilitar a sua prática foram criados percursos pedestres sinalizados que têm por finalidade conduzir os praticantes que os percorrem.

A oferta de percursos sinalizados é cada vez mais abrangente em termos geográficos, tornando a atividade cada vez mais acessível a um maior número de pessoas.

Ao mesmo tempo, o crescente número de praticantes elevou a prática de um lazer informal a uma verdadeira ação turística.

A presente reflexão pretende contextualizar, no plano internacional, as temáticas do pedestrianismo, percursos pedestres e turismo de passeio pedestre, e para o caso de Portugal, explicitar a distribuição territorial dos percursos pedestres homologados (pela Federação Portuguesa de 
Campismo e Montanhismo), assim como apresentar uma análise exploratória da oferta de turismo de passeio pedestre (com base em empresas de animação turística e agências de viagens licenciadas).

\section{Pedestrianismo e Percursos Pedestres}

Caminhar pelo puro prazer de caminhar, para explorar, por razões de saúde e bem-estar físico e espiritual, pelo convívio, para conhecer os próprios limites, para contemplar paisagens, para observar a natureza, como forma de escapar à vida de todos os dias, utilizando caminhos ou trilhos existentes, é a atividade a que se dá o nome de pedestrianismo, cada vez mais popular nas sociedades desenvolvidas. Expressões, em português, como caminhar, andar a pé, praticar pedestrianismo, ou walking, hiking (EUA) ou rambling (Reino Unido), em inglês, encontram-se na literatura e referem-se todas à mesma atividade de andar a pé, em trilhos sinalizados ou promovidos para esse fim. A palavra trekking, também associada à mesma atividade, utiliza-se para designar as "deslocações a pé, de alguns dias, em grande parte através de carreiros ou trilhos, em zonas montanhosas sem ligação a outras vias de comunicação" (Bietolini, 2007: 8).

Segundo Kouchner e Lyard (2001), o pedestrianismo envolve cerca de 3 milhões de praticantes em Itália, 10 milhões no Reino Unido e $30 \%$ dos suecos dedicam-se ao passeio em florestas ou caminhos rurais. Afirmam ainda que esta atividade está em forte expansão em todos os países. De acordo com o Ministério da Saúde e dos Desportos francês, o número de pedestrianistas em França atinge os 5 milhões de praticantes (EG, 2009).

Embora não seja fácil encontrar dados sobre o número de praticantes de pedestrianismo, é notória a dimensão da atividade, a nível europeu, pela quantidade de grupos organizados ligados à prática de andar a pé. A European Ramblers Association (ERA), fundada em 1969 na Alemanha, com os objetivos de criação e melhoria de condições para a prática de pedestrianismo, integra mais de 50 organizações de 26 países europeus e conta com cerca de 5 milhões de membros individuais. 
O pedestrianismo apresenta um conjunto de fatores que contribuem para a sua popularidade e crescimento entre as atividades de lazer: é uma atividade de baixo custo para o praticante e pouco exigente em termos de forma física, sendo praticado por mulheres, crianças e pessoas pertencentes às faixas etárias mais elevadas. A oferta de percursos sinalizados é cada vez mais abrangente em termos geográficos, tornando a atividade mais acessível a um maior número de pessoas.

$\mathrm{O}$ ato de andar a pé, em percursos pedestres, está muito associado a um estilo de vida saudável, não só pelo exercício físico em si, mas também pelo convívio social e por ser uma atividade que se pratica ao ar livre, preferencialmente em contato com a natureza. Embora seja praticado em qualquer tipo de meio, é com os espaços naturais que o pedestrianismo tem maior relação.

Os territórios de montanha, pela sua especificidade, tiveram e continuam a representar um papel importante no desenvolvimento do pedestrianismo. Os Alpes, os Pirenéus e os Picos da Europa são destinos de referência, com uma ampla oferta de possíveis percursos pedestres, com bons suportes de informação, traduzidos em várias línguas, serviços de guia, e estruturas de apoio, como alojamento e abrigos, nas proximidades dos percursos.

Os percursos pedestres, ou trilhos, constituem a principal infra-estrutura ou equipamento para a prática de pedestrianismo. A sua conceção não obedece a regras rígidas e uniformes quanto, por exemplo, à localização, aos utilizadores, à forma, à extensão, à sinalização e à manutenção.

A criação de um percurso pedestre, que constitui muitas vezes uma forma de revitalização de caminhos antigos, implica um conjunto de intervenções, para que os seus utilizadores se sintam seguros e confortáveis quando o percorrem, que podem incluir, por exemplo, ações de desmatação e limpeza, colocação de proteções laterais em passagens menos seguras, construção de pequenas pontes, instalação de áreas de descanso e sinalização (figura 1).

A forma e dimensão dos percursos são variáveis. Quanto à forma, distinguem-se em duas grandes categorias: linear e circular. Num percurso linear ou aberto, o ponto de partida é diferente do ponto de chegada. O percurso circular, também denominado fechado, é aquele em que o 
ponto de partida e o ponto de chegada são coincidentes. Especificando um pouco mais, podem enumerar-se outras configurações de percursos, além das indicadas, atendendo à forma do seu traçado. Braga (2007) refere ainda as formas em oito, em anéis contíguos, em anéis satélites e em labirinto.

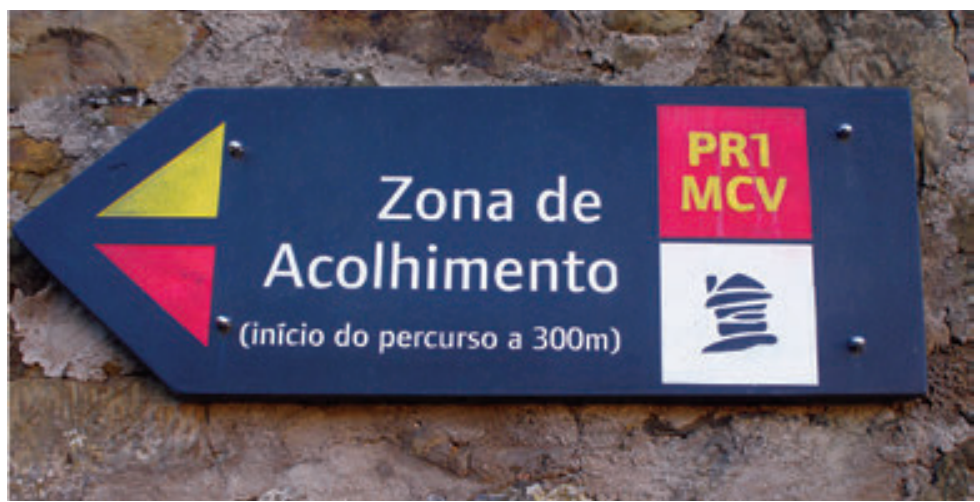

Figura 1. Placa indicativa/informativa de percurso pedestre ("Caminhos do Xisto") em Gondramaz (Miranda do Corvo, 2009)

Foto: Paulo Carvalho

Quanto à sua extensão, a oferta abrange uma larga amplitude, podendo dividir-se em dois grandes grupos: os percursos de grande extensão, de itinerância, que atravessam regiões ou mesmo países, que não se percorrem num dia, e os percursos de menor dimensão, que podem ser percorridos numa jornada. Os primeiros são denominados percursos de Grande Rota (GR) e têm, geralmente uma extensão superior a $30 \mathrm{~km}$. Os segundos são os percursos de Pequena Rota (PR) e a sua extensão não deve exceder os $30 \mathrm{~km}$.

A Europa é atravessada por uma rede de 11 percursos de Grande Rota que se desenvolve através de vários países, num total de quase 55000 quilómetros. Constituem eixos de uma imensa rede que integra milhares de quilómetros de percursos locais, de dimensão variável e articulando-se de forma a satisfazer diferentes tipos de utilizadores. Partes destes percursos sobrepõem-se a algumas rotas históricas, como a mítica GR65, o caminho francês de peregrinação a Santiago de Compostela. 
A disponibilidade de informação sobre percursos pedestres, em várias línguas, reflete de certa maneira a maturidade da atividade em determinada região ou país e pode condicionar a sua capacidade de atrair visitantes do exterior para a prática de pedestrianismo. Para a grande parte das redes de percursos existentes na Europa, a informação encontra-se dispersa e apenas disponível na língua do próprio país em que se encontram.

Têm particular importância os percursos de montanha, nomeadamente em termos de promoção exterior, em países como a Áustria, Bulgária, França, Eslováquia, Espanha, Roménia e Suíça e especialmente nas regiões dos Alpes e Pirenéus.

\section{Turismo de Passeio Pedestre}

Como referem Kouchner e Lyard (2001: 5), "ignorado ou subestimado durante muito tempo, o turismo de passeio pedestre é hoje considerado como um desafio ao desenvolvimento local. Sendo atualmente uma atividade muito divulgada entre a população dos países europeus, o passeio evolui, passando da categoria de um lazer informal para uma verdadeira ação turística, potencialmente geradora de benefícios a nível local.”

O passeio pedestre, cada vez mais presente nos hábitos de lazer da população europeia, tem assumido uma importância crescente também ao nível da revitalização de espaços, nomeadamente rurais, naturais e de montanha, turísticos ou não, onde novos produtos turísticos se apresentam como alternativa de desenvolvimento, face ao declínio das atividades e/ ou ofertas tradicionais.

Embora cerca de $80 \%$ dos turistas não vão de férias para praticar uma atividade específica, pelo menos metade participa numa atividade de ar livre no destino (Mintel, 1998, citado por Tribe, Font, Griffiths, Vickery, Yale, 2000). Os percursos pedestres assumem, assim, importância no destino, como uma oferta complementar capaz de enriquecer a experiência dos turistas durante a sua estada. Podem também assumir o papel principal no produto turístico e constituírem a razão da deslocação ao destino. 
Os produtos turísticos baseados no passeio pedestre, disponíveis para compra on-line, não são escassos. Existem operadores especializados neste tipo de produto que organizam programas de vários dias de caminhadas em diferentes destinos do globo.

Os produtos de turismo de passeio pedestre podem assumir diferentes configurações:

- Férias com tudo incluído: o operador organiza os transportes, alojamento, refeições e serviço de guia para as caminhadas diárias. Geralmente para se realizarem, exigem um número mínimo de participantes;

- Férias auto-guiadas: o operador faz a reserva de alojamento e fornece ao cliente mapas, guias, roteiros e toda a informação e conselhos necessários para que este possa percorrer, de forma autónoma, um conjunto de percursos no destino; pode haver mudança de alojamento e, neste caso, normalmente existe serviço de transporte de bagagens; nestes programas é exigido um número mínimo de dois participantes;

- Férias itinerantes: consistem em percorrer um itinerário, ao longo de vários dias, mudando de alojamento todas as noites. Podem ser guiadas ou auto-guiadas. Incluem, geralmente, o transporte de bagagens entre os alojamentos;

- Férias centradas num local de alojamento, com saídas diárias para percursos diferentes ou para pontos diferentes de um grande itinerário. Incluem o transporte diário do alojamento para o local de início do percurso e regresso. Normalmente são passeios guiados, mas também podem ser auto-guiados;

- Serviços individuais: alguns operadores vendem serviços avulsos, a pedido do cliente, como por exemplo reserva de alojamento, guias locais no destino ou transporte de bagagens entre pontos de um itinerário definido pelo cliente.

Os destinos são, de igual modo, diversificados. Encontram-se programas para os quatro cantos do mundo. Os destinos de montanha como os Alpes, os Pirenéus, os Picos da Europa, os Atlas, os Himalaias ou os Andes são destinos de eleição para este tipo de produto turístico. 
Como exemplo, apresentam-se três programas oferecidos por operadores europeus, especializados em turismo de passeio pedestre (quadro I).

\section{QUADRo I - Programas de turismo de passeio pedestre}

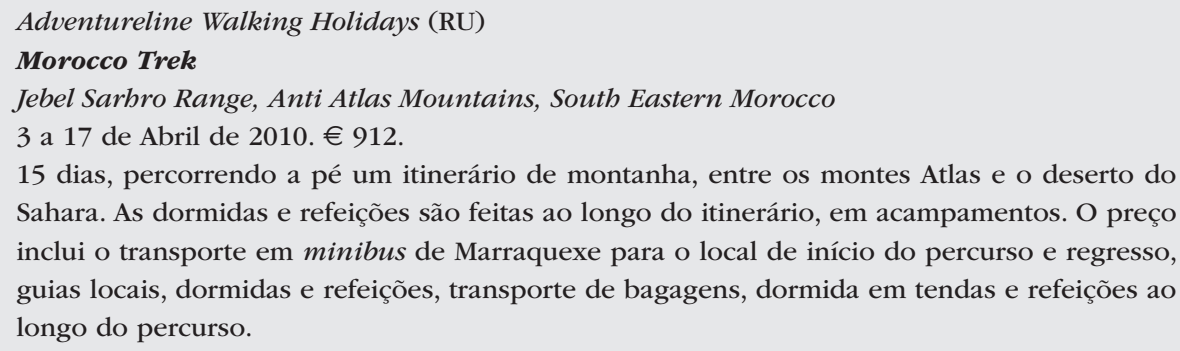

\section{La Pélerine (França)}

\section{Les Balcons d'Azur - en traversée liberte}

17 de Setembro de 2009 a 31 de Dezembro de 2009; mínimo 2 participantes; $€ 530$.

7 dias, 5 dos quais percorrendo a pé um itinerário, de forma autónoma (sem guia), com alojamento em hotéis. O preço inclui o alojamento em quarto duplo, em regime de meia-pensão, transporte de bagagens e informação detalhada sobre o percurso.

\section{A2Z Adventures (Portugal)}

\section{Trekking - Patagonia Expedition}

22 de Novembro a 9 de Dezembro de 2009; $€ 1590$.

Programa de 18 dias, incluindo 6 dias de marcha (6 a 8 horas de marcha diária).

Inclui 1 guia bilingue, transporte de bagagens, alojamento (hotéis, bostels e acampamento) e refeições.

Fonte: Adventureline, La Pélerine e A2Z Adventures, 2009

A generalidade da oferta de produtos turísticos que têm por base o passeio pedestre, levam os seus participantes a conhecer áreas de paisagens de elevada qualidade, costumes e tradições das regiões visitadas, oferecendo serviços altamente especializados e um certo grau de exclusividade. O nível e tipo de serviços variam de programa para programa. Por exemplo, no que diz respeito ao alojamento, todas as fórmulas e tipologias são permitidas: o hotel, o turismo rural, o acampamento, ou os abrigos de montanha, podendo mesmo acontecer um pacote incluir uma noite num hotel, outra noite num abrigo de montanha e outra noite num turismo rural. No desenho do produto de passeio pedestre, o elo 
central são os percursos. O alojamento e refeições, idealmente salvaguardando a qualidade e autenticidade, são os que satisfazem melhor as condições de usufruto dos percursos e variam muito consoante o destino.

Pela sua relação com o território e com o meio natural, a maioria destes programas enquadra-se no âmbito do turismo de natureza, onde, por definição, a motivação principal é a de "viver experiências de grande valor simbólico, interagir e usufruir da Natureza" (THR, 2006). O turismo de natureza, de acordo com o Plano Estratégico Nacional de Turismo (2007), faz parte do conjunto de 10 produtos turísticos estratégicos para Portugal, definidos tendo em conta as caraterísticas do país e o potencial de crescimento do mercado.

\section{Percursos Pedestres em Portugal}

Em Portugal, a promoção da prática de pedestrianismo, bem como o registo, homologação e divulgação de percursos pedestres é da responsabilidade da Federação de Campismo e Montanhismo de Portugal (FCMP), antiga Federação Portuguesa de Campismo.

A marcação de percursos pedestres obedece a um conjunto de normas que se encontram descritas no manual "Percursos Pedestres - Normas para Implantação e Marcação", promovido e difundido pela Federação Portuguesa de Campismo, desde 1994. Este pequeno manual veio contribuir para a uniformização da sinalização utilizada na marcação de percursos pedestres em Portugal, contrariando "a forma desregrada e sem nexo com que assistimos à marcação de percursos das formas mais diversas, com utilização de cores e marcas ao gosto de cada um, sem preocupação pela uniformização, às vezes importadas de sítios longínquos e inadequadas a Portugal" (FPC, 2000: 4).

Em Portugal, o primeiro percurso pedestre foi homologado em 1997. Trata-se do PR1 "Rota da Serra”, um percurso pedestre circular, com 17 km, no concelho de Grândola, promovido pelo CIMO - Clube Ibérico de Montanhismo e Orientação, com sede em Almada (Gonçalves, 2002). Entre os anos de 1998 e 2002 foram homologados 30 percursos pedestres: 
4 percursos em 1998, 5 percursos por ano em 1999, 2000 e 2001 e 11 percursos em 2002 (Gonçalves, 2002).

De acordo com dados da FCMP, existem atualmente em Portugal cerca de $3400 \mathrm{~km}$ de percursos pedestres homologados, que se distribuem pelas 7 regiões do país, de acordo com o descrito no quadro II. Destacam-se as regiões Norte $(1025,6 \mathrm{~km})$, Centro $(761,5 \mathrm{~km})$ e Algarve $(755,8 \mathrm{~km})$, que em conjunto perfazem $2542,9 \mathrm{~km}$ de percursos pedestres homologados, ou seja, $76 \%$ do total.

O total de quilómetros de percursos apresentado corresponde a percursos de pequena rota e percursos de grande rota, sendo a maioria de pequena rota (cerca de $71 \%$ ), ou seja, percursos que se percorrem numa jornada, geralmente com extensão inferior a $30 \mathrm{~km}$.

De acordo com os dados apresentados, o continente português apresenta $98,8 \%$ do número de percursos pedestres de pequena rota e concentra $99,2 \%$ do total de quilómetros. A região Norte é a região com maior número e total de quilómetros de percursos pedestres de pequena rota, seguindo-se a região Centro, o Algarve, o Alentejo e Lisboa. A região dos Açores não tem qualquer percurso pedestre homologado e a região da Madeira tem apenas 3 percursos pedestres, com um total de $18,8 \mathrm{~km}$.

QUADRo II - Número e quilómetros de percursos pedestres homologados, por região, até Abril de 2009

\begin{tabular}{|l|c|r|r|r|r|}
\hline \multirow{2}{*}{ Região } & \multicolumn{2}{|c|}{ Pequena Rota } & \multicolumn{2}{c|}{ Grande Rota } & Total (Kms) \\
\hline & $\mathrm{N}^{\mathrm{o}}$ de percursos & $\mathrm{Kms}$ & $\mathrm{N}^{\mathrm{o}}$ de percursos & \multicolumn{1}{c|}{ Kms } & \\
\hline Norte & 69 & 734,5 & 5 & 291,1 & 1025,6 \\
\hline Centro & 59 & 578,7 & 3 & 182,8 & 761,5 \\
\hline Lisboa & 20 & 139,5 & 2 & 162 & 301,5 \\
\hline Alentejo & 48 & 406,6 & 2 & 78 & 484,6 \\
\hline Algarve & 51 & 488,8 & 2 & 267 & 755,8 \\
\hline Açores & 0 & 0 & 0 & 0 & 0 \\
\hline Madeira & 3 & 18,8 & 0 & 0 & 18,8 \\
\hline TOTAL & $\mathbf{2 5 0}$ & $\mathbf{2 3 6 6 , 9}$ & $\mathbf{1 4}$ & $\mathbf{9 8 0 , 9}$ & $\mathbf{3 3 4 7 , 8}$ \\
\hline
\end{tabular}

Fonte: Tovar, 2010 
Os percursos pedestres de grande rota, homologados, estendem-se por quase $1000 \mathrm{~km}$ do território de Portugal continental.

Os arquipélagos dos Açores e Madeira não têm percursos pedestres de grande rota homologados.

A região Norte é a região que possui maior número de quilómetros de percursos pedestres de grande rota homologados, seguindo-se o Algarve, a região Centro, Lisboa e, por fim, o Alentejo.

FIgURA 2. Distribuição territorial dos percursos pedestres homologados em Portugal
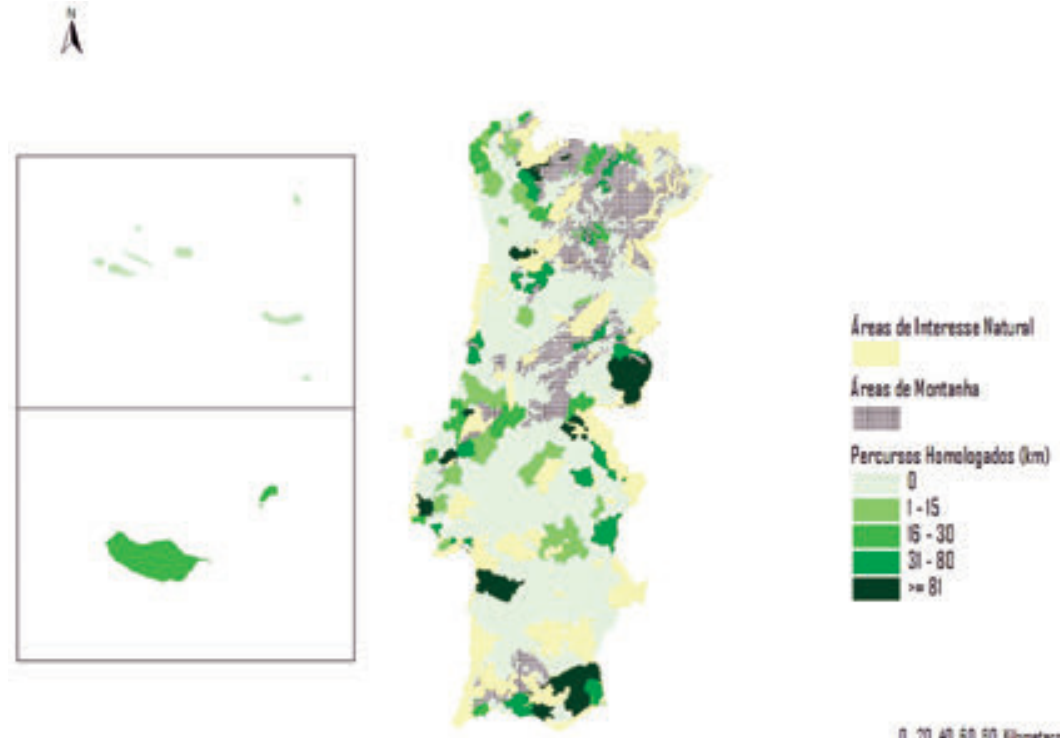

Fonte: Tovar, 2010

A figura 2 mostra a distribuição de percursos pedestres homologados - total de quilómetros, por concelho, de percursos pedestres de pequena rota e percursos pedestres de grande rota - bem como a localização das principais áreas de interesse natural, incluindo as áreas pertencentes à Rede Nacional de Áreas Protegidas e a Rede Natura 2000, e as principais áreas de montanha. Para os territórios dos arquipélagos dos Açores e Madeira não se inclui informação relativa ao relevo e às principais áreas 
de interesse natural, apenas se considerou o total de quilómetros de percursos homologados existentes em cada um dos arquipélagos, que é nulo no arquipélago dos Açores e de cerca de $20 \mathrm{~km}$ na Madeira, no concelho do Funchal.

A observação do mapa permite verificar que os concelhos em que existe maior número de quilómetros de percursos homologados, com mais de 81 quilómetros de percursos, se situam em áreas de grande interesse natural (com estatutos de proteção nacional e internacional), como são os casos dos concelhos:

- Terras de Bouro e Montalegre, no Parque Nacional da Peneda-Gerês, e o concelho vizinho de Vieira do Minho;

- Arouca, que integra a Zona Especial de Conservação (ZEC) das Serras da Freita e Arada (PTCON0047);

- Idanha-a-Nova, com a Zona de Proteção Especial (ZPE) Tejo Internacional, Erges e Pônsul (PTZPE0042);

- Nisa, muito próximo do Parque Natural da Serra de S. Mamede, com grande parte da sua área na ZEC de São Mamede (PTCON0007);

- Porto de Mós, no Parque Natural das Serras de Aire e Candeeiros;

- Cadaval, na Área de Protegida da Serra de Montejunto;

- Sintra, no Parque Natural de Sintra-Cascais;

- Grândola, que integra a ZEC Comporta/Galé (PTCON0034);

- Loulé e Tavira, no Parque Natural da Ria Formosa;

- Alcoutim, que integra a ZEC Guadiana (PTCON0036).

É ainda de realçar que estes concelhos, que dominam o panorama nacional em termos de quilómetros de percursos pedestres homologados, têm no seu território importantes áreas de montanha, como as Serras da Peneda e Gerês, Serra da Freita, Serra de Penha Garcia, Serras de Aire e Candeeiros, Serra de Montejunto, Serra de Sintra, Serra de Grândola, Serra de S. Mamede e Serra do Caldeirão.

Os concelhos que se enquadram no nível imediatamente abaixo, em número de quilómetros de percursos homologados, na categoria "31-80 km”, são concelhos que se situam na vizinhança dos primeiros. 
Destacam-se no mapa áreas formadas por conjuntos de concelhos, vizinhos uns dos outros, com assinalável ocorrência de percursos pedestres homologados:

- A área junto à fronteira Norte do país, desde Melgaço até Bragança, que se estende para Sul englobando os concelhos de Guimarães e Amarante, estendendo-se pelo litoral, entre Valença e Póvoa do Varzim;

- A área de Arouca, S. Pedro do Sul e Vouzela;

- A área de Penamacor e Idanha-a-Nova;

- A região das Serras de Aire e Candeeiros e Serra de Montejunto e o seu prolongamento para o litoral, formando uma faixa, nem sempre contínua, entre Leiria e Grândola;

- Por fim, a terceira área do país em número de quilómetros de percursos homologados - a região do Algarve - que apresenta uma superfície bem definida e de expressiva continuidade.

A distribuição geográfica dos percursos pedestres pelo território nacional reflete que existem áreas, com caraterísticas comuns, onde a oferta é mais visível. Estas caraterísticas comuns são a riqueza do património natural e uma localização em ambiente de montanha.

Apesar das competências e dos esforços da FCMP, no sentido de promover o pedestrianismo em Portugal e apelar à homologação e registo de percursos, os recursos reais existentes para a prática desta atividade são bem mais extensos que os dados apresentados. De fato, existe uma grande quantidade de percursos pedestres que não se encontram homologados e consequentemente não integram o Registo Nacional de Percursos Pedestres.

Nas regiões da Madeira e dos Açores existe legislação regional relativa aos percursos pedestres (Decreto Legislativo Regional n. ${ }^{\circ}$ 7-B/2000/M e Decreto Legislativo Regional n. $\left.{ }^{\circ} 16 / 2004 / A\right)$, o que pode explicar a quase inexistência de percursos pedestres homologados de acordo com as normas da Federação de Campismo e Montanhismo de Portugal. A leitura dos referidos decretos mostra que os percursos pedestres são reconhecidos, nestas regiões autónomas, como um importante recurso turístico. 


\section{Turismo de Passeio Pedestre em Portugal}

Em Portugal, a organização e venda de atividades recreativas, desportivas ou culturais, em meio natural ou em instalações fixas, de caráter lúdico, com interesse turístico para a região onde se desenvolvam é uma atividade própria das empresas de animação turística (MEI, 2009). Os passeios pedestres enquadram-se neste tipo de atividades e a sua organização, com fins comerciais, é feita principalmente pelas empresas de animação turística. No quadro legal que estabelece as condições de acesso e de exercício da atividade destas empresas, o artigo $5 .^{\circ}$ refere que também é permitida a organização de programas de passeio pedestre pelas agências de viagens e empreendimentos turísticos, desde que previsto no seu objeto e desde que cumpram o mesmo tipo de condições exigidas às empresas de animação turística, nomeadamente em termos de seguros obrigatórios de acidentes pessoais e de responsabilidade civil.

O Turismo de Portugal mantém um registo das empresas de animação turística e agências de viagens existentes em Portugal, a partir do qual foi possível identificar 161 empresas registadas como organizadoras de programas de passeio pedestre distribuídas da seguinte forma pelas sete regiões do país: Açores (10\%), Alentejo (9\%), Algarve (7\%), Centro (14\%), Lisboa (24\%), Madeira (10\%) e Norte (26\%). Existem empresas com oferta de passeios pedestres em todas as regiões do país. Metade das empresas portuguesas, registadas como organizadoras de programas de passeios pedestres, é originária das regiões Norte e Lisboa.

A distribuição geográfica das empresas não permite tirar conclusões sobre os locais onde se realizam os passeios. Para tal, e com recurso à Internet, foram analisados os programas, disponíveis on-line, destas empresas.

De acordo com a THR (2006), em Portugal, 98\% das empresas que operam no setor do turismo de natureza, promovem a sua oferta através da Internet. Se bem que a grande maioria das empresas tenha presença na Internet, das 161 empresas inventariadas apenas 62 apresentam on-line programas de passeio pedestre. É de referir que muitas das empresas registadas como organizadoras de passeios pedestres, não apresentam, de 
fato, este tipo de programa. Foram listados e analisados 487 programas de operadores portugueses, com o passeio pedestre como componente principal.

Contudo, a organização de passeios pedestres em Portugal não é exclusiva das empresas portuguesas, também operadores estrangeiros organizam este tipo de programas no nosso país. A pesquisa na Internet, utilizando o motor de busca Google, inserindo as expressões "walking holidays Portugal" e "walk in Portugal", permitiu identificar um importante conjunto de operadores estrangeiros que vendem férias de passeio pedestre em Portugal, essencialmente produtos que, pela forma como são apresentados, apelando à beleza da paisagem e riqueza natural, se enquadram na esfera do turismo de natureza.

Da pesquisa exploratória realizada, e reconhecendo que foi dada, pelo critério de busca utilizando expressões em língua inglesa, primazia aos operadores que se dirigem ao público anglófono, foram encontrados 23 operadores do Reino Unido, Estados Unidos da América e Austrália, com oferta de 104 programas de férias de passeio pedestre em Portugal. Tal como para os operadores portugueses, consideraram-se apenas os programas que têm o passeio pedestre como componente principal, excluindo-se os programas multi-atividades.

\section{QUADRO III - Exemplo de programa de turismo de passeio pedestre em Portugal}

\section{Waterways \& Flowers}

Madeira, a verdant paradise

Nights: 7

Grade: 2 (a head for heights is required on some short sections of the levada walks)

Terrain: levadas, paths and tracks in the mountains

Accommodation: one 3-star; one 4-star; two 5-star quintas

Meals: dinner \& breakfast each day, plus 3 picnics

Available 1 May 2008-31 October 2009

$£ 628$ to $£ 698$

Fonte: Inntravel, 2009 
Os programas oferecidos pelos operadores portugueses e estrangeiros têm duração de 1 ou vários dias. Aqueles que têm duração superior a 1 dia apresentam-se nas diferentes modalidades de férias de passeio pedestre. Há programas que incluem o transporte para o destino - a viagem de avião, no caso de operadores estrangeiros - outros que apenas incluem os serviços no destino. Há diferentes tipologias de alojamento utilizadas e também diferentes modalidades no que diz respeito às refeições.

No caso dos programas de 1 dia, estes consistem, geralmente, num passeio pedestre guiado, temático ou não.

Os programas foram analisados considerando essencialmente o destino e a duração, permitindo uma visualização territorial da oferta de turismo de passeio pedestre em Portugal.

Os programas promovidos, tanto pelos operadores portugueses como pelos estrangeiros, cobrem a totalidade do território nacional. Os destinos mais representados situam-se nas regiões Norte e Lisboa, acolhendo estas regiões quase metade (47\%) de todos os programas oferecidos em território nacional (figura 3).

Figura 3. Programas de turismo de passeio pedestre em Portugal, por região

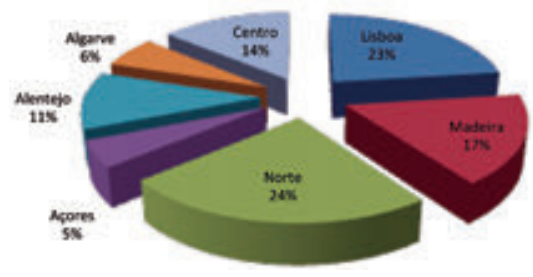

Analisando em separado os destinos constantes nos programas dos operadores portugueses e dos operadores estrangeiros, verifica-se que os programas oferecidos pelos operadores portugueses refletem a localização dos próprios operadores.

Tendencialmente, um operador português organiza programas dentro da sua própria região, o que é natural, pois a organização deste tipo de programas exige um profundo conhecimento do território. 
Em relação aos destinos preferidos pelos operadores estrangeiros, de acordo com os programas analisados, têm maior importância as regiões Madeira e Norte, seguidas do Algarve, Alentejo e Açores. As regiões Centro e Lisboa ocorrem com uma frequência quase residual nos seus programas.

Os programas de passeio pedestre analisados têm duração variável, encontrando-se com maior frequência programas com duração de vários dias nos operadores estrangeiros e programas com duração inferior, frequentemente de um dia apenas, nos operadores portugueses (quadro IV).

QUADRo IV - Duração dos programas de turismo de passeio pedestre em Portugal, por operador

\begin{tabular}{|c|c|c|c|c|c|c|}
\hline \multirow{2}{*}{ Operador } & \multicolumn{6}{|c|}{ Duração dos programas, em dias } \\
\hline & 1 & 2 e 3 & 4 a 6 & 7 e 8 & 9 e 10 & $>=11$ \\
\hline Operadores portugueses & 407 & 57 & 4 & 15 & 2 & 2 \\
\hline Operadores estrangeiros & 0 & 0 & 12 & 81 & 1 & 9 \\
\hline Total & 407 & 57 & 16 & 96 & 3 & 11 \\
\hline
\end{tabular}

Fonte: Tovar, 2010

Os programas oferecidos pelos operadores estrangeiros têm uma duração de 4 ou mais dias, sendo mais frequentes os programas de 7 ou 8 dias.

Dos programas de turismo de passeio pedestre, de 2 ou mais dias, oferecidos pelos operadores portugueses, ocorrem com maior frequência os programas de fim-de-semana ( 2 e 3 dias), seguindo-se os programas semanais, com 7 ou 8 dias.

Grande parte dos programas organizados por empresas portuguesas, é de 1 dia, sendo escassa, em comparação com o que oferecem os operadores estrangeiros, a oferta de programas com duração superior a 4 dias.

Considerando apenas os programas com 2 ou mais dias de duração, e analisando uma vez mais os principais destinos, verifica-se que as regiões mais importantes são o Norte (30\%), a Madeira (18\%) e as regiões Centro, Alentejo e Algarve (14\%) (quadro V). 
QUADro V - Duração dos programas de turismo de passeio pedestre em Portugal, por região

\begin{tabular}{|l|c|c|c|c|c|c|c|c|c|}
\hline \multirow{2}{*}{ Região } & \multicolumn{5}{|c|}{ Duração dos programas, em dias } & \multicolumn{4}{c|}{ N. ${ }^{\circ}$ Programas } \\
\cline { 2 - 11 } & $\mathbf{1}$ & $\mathbf{2}$ e 3 & $\mathbf{4}$ a 6 & $\mathbf{7}$ e 8 & $\mathbf{9}$ e 10 & >=11 & TOTAL & $\%$ 1 dia* $^{*}$ & $\%$ dia $^{* * *}$ \\
\hline Açores & 20 & 1 & 1 & 6 & 0 & 4 & 32 & $5 \%$ & $7 \%$ \\
\hline Alentejo & 37 & 5 & 1 & 18 & 0 & 2 & 63 & $9 \%$ & $14 \%$ \\
\hline Algarve & 8 & 4 & 1 & 19 & 0 & 1 & 33 & $2 \%$ & $14 \%$ \\
\hline Centro & 57 & 19 & 1 & 6 & 0 & 0 & 83 & $14 \%$ & $14 \%$ \\
\hline Lisboa & 130 & 1 & 4 & 0 & 0 & 0 & 135 & $32 \%$ & $3 \%$ \\
\hline Madeira & 65 & 1 & 1 & 26 & 3 & 2 & 98 & $16 \%$ & $18 \%$ \\
\hline Norte & 90 & 26 & 7 & 21 & 0 & 2 & 146 & $22 \%$ & $30 \%$ \\
\hline TOTAL & 407 & 57 & 16 & 96 & 3 & 11 & 590 & $100 \%$ & $100 \%$ \\
\hline
\end{tabular}

Fonte: Tovar, 2010

* \% de programas de 1 dia em relação ao total de programas de 1 dia

** \% de programas de 2 ou mais dias em relação ao total de programas de 2 ou mais dias

Com um número muito significativo de programas de passeio pedestre de 1 dia, a região de Lisboa perde importância como destino de turismo de passeio pedestre, quando se consideram apenas os programas com duração superior, figurando em apenas 3\% destes programas. A região dos Açores, embora com menor número de programas que as restantes regiões (com exceção de Lisboa), é a região que apresenta maior número de programas com duração superior a 11 dias. Estes incluem a visita a mais do que uma ilha do arquipélago (quadro V).

Os programas de passeio pedestre de 1 semana (7 ou 8 dias) são os mais frequentes em Portugal, seguindo-se os programas de fim-de-semana ou fim-de-semana alargado, com 2 a 6 dias de duração.

Observando a duração dos programas (mais de 1 dia) em cada uma das regiões destino (quadro V), podem classificar-se os destinos, de acordo com a duração mais frequente dos programas que acolhem:

- Os Açores, Alentejo, Algarve e Madeira são destinos de programas de $7 / 8$ dias;

- O Centro é destino de programas de 2/3 dias; 
- O Norte é destino de programas de $2 / 3$ dias e $7 / 8$ dias;

- A região de Lisboa apresenta um número residual de programas, sendo os mais frequentes os de 4 a 6 dias.

Em cada uma das 7 grandes regiões - Açores, Alentejo, Algarve, Centro, Lisboa, Madeira e Norte - é possível identificar destinos mais específicos, que constam com maior frequência nos programas de turismo de passeio pedestre (quadro VI).

QuAdro VI. Principais destinos de turismo de passeio pedestre nos programas consultados

\begin{tabular}{|l|c|l|c|l|c|}
\hline \multicolumn{2}{|l|}{ Açores } & Algarve & \multicolumn{2}{l|}{ Lisboa } \\
\hline Açores & $36 \%$ & Algarve & $46 \%$ & Lisboa & $7 \%$ \\
\hline Pico & $23 \%$ & Costa Vicentina & $20 \%$ & PN Serra da Arrábida & $30 \%$ \\
\hline S. Miguel & $35 \%$ & Monchique & $20 \%$ & PN Sintra-Cascais & $38 \%$ \\
\hline Outros & $6 \%$ & Outros & $14 \%$ & Outros & $25 \%$ \\
\hline Alentejo & $32 \%$ & Centro & $1 \%$ & Norte & $6 \%$ \\
\hline Alentejo & $11 \%$ & PN Serra da Estrela & $26 \%$ & PN Peneda-Gerês & $34 \%$ \\
\hline PN S. São Mamede & $8 \%$ & Aldeias Históricas & $11 \%$ & Douro & $15 \%$ \\
\hline Évora & $38 \%$ & $\begin{array}{l}\text { Aldeias do Xisto e } \\
\text { Serra da Lousã }\end{array}$ & $29 \%$ & Serra de Arga & $5 \%$ \\
\hline Costa Alentejana & $11 \%$ & Outros & $33 \%$ & Outros & $40 \%$ \\
\hline Outros & & & & Norte \\
\hline
\end{tabular}

Fonte: Tovar, 2010

Dos programas analisados para a região dos Açores, grande parte não menciona o local exato onde se desenvolvem; $35 \%$ destes têm a ilha de $\mathrm{S}$. Miguel como destino e $23 \%$ a ilha do Pico, onde têm relevância os programas de subida ao ponto mais alto de Portugal. Em "outros" destacam-se os programas que envolvem várias ilhas, programas no Faial e na ilha de S. Jorge.

No Alentejo, a preferência dos operadores é a Costa Alentejana, desde Grândola até Odeceixe, integrando a área do Parque Natural do Sudoeste Alentejano e Costa Vicentina. A área do Parque Natural da Serra de São 
Mamede é também um importante destino de turismo de passeio pedestre, na região Alentejo. Em “outros”, encontram-se programas no vale do Guadiana e Mértola, Monsaraz, Serra de Ossa e Estuário do Sado.

Os programas de turismo de passeio pedestre no Algarve apresentam-se para os destinos Algarve, de forma genérica, Monchique, ou Serra de Monchique, e Costa Vicentina. A Costa Vicentina estende-se desde a ponta de Sagres até Odeceixe, onde se encontra a fronteira com o Alentejo. Esta área da costa ocidental algarvia, que integra o Parque Natural do Sudoeste Alentejano e Costa Vicentina, tem um peso importante nos destinos algarvios de passeio pedestre.

A região Centro apresenta grande fragmentação de destinos de passeio pedestre, muito poucos se identificando por "Centro". Destinos como Aldeias do Xisto e Serra da Lousã, Parque Natural da Serra da Estrela ou Aldeias Históricas, são de grande importância. Em “Outros” inclui-se grande variedade de destinos como Vale do Ceira, Oliveira do Hospital, Serra do Açor, Serra do Caramulo, Serra da Gardunha, Serra de Sicó, entre outros. A região apresenta uma importante área de montanhas (Cordilheira Central) que se estende de Nordeste para Sudoeste e integra as serras da Estrela, Açor, Lousã, Malcata, Gardunha, Muradal e Alvelos, entre outras, com áreas de paisagem de grande beleza e ainda pouco exploradas, que constituem destinos quase exclusivos do rol de ofertas das empresas de animação turística locais. Os operadores estrangeiros têm uma atuação muito reduzida nesta região. Foram encontrados apenas 2 programas, com duração de 8 dias, em Belmonte (Aldeias Históricas).

Essencialmente destino de programas de 1 dia, a região de Lisboa apresenta duas áreas privilegiadas para a realização de passeios pedestres: o Parque Natural da Serra da Arrábida e o Parque Natural de Sintra-Cascais. Outros destinos, nesta região, são a Tapada de Mafra, Serra de Montejunto, Serras de Aire e Candeeiros, Costa da Caparica, Sesimbra e Estuário do Tejo.

A região Norte é a única região do país que integra um Parque Nacional - o Parque Nacional da Peneda-Gerês (PNPG) - que representa, segundo os programas analisados, uma das mais importantes áreas, em Portugal, para a prática de pedestrianismo. No contexto nacional, em números 
absolutos, é o segundo destino de passeio pedestre mais importante de Portugal continental, sendo apenas superado pelo Parque Natural de Sintra-Cascais, na região de Lisboa.

A região do Douro é também um importante destino de turismo de passeio pedestre, no Norte de Portugal. Esta região apresenta importância relevante nos programas dos operadores estrangeiros e assume a posição de destino mais importante, no Norte de Portugal, quando se consideram apenas os programas com 2 ou mais dias. Em "Outros", encontram-se destinos como a Serra da Freita, Serra de Arga, Vale do Lima, Viana do Castelo, Parque Natural de Montesinho, entre outros.

A região da Madeira aparece, em grande parte dos programas, como destino em si. Os programas, de uma forma genérica, referem "Madeira" ou "Levadas da Madeira". Assim, no caso desta região, não são considerados diferentes destinos mais específicos.

De acordo com o exposto, pode concluir-se que para todas as regiões de Portugal, existe oferta de programas de turismo de passeio pedestre. Esta oferta ocorre com maior frequência em áreas de grande interesse natural e em áreas de montanha (geralmente coincidentes).

Destacam-se as regiões Norte e Lisboa, quando se consideram programas de 1 dia. A apreciação de programas com duração superior confirma a importância da região Norte, e faz sobressair também as regiões da Madeira, Algarve, Alentejo e Centro, como principais destinos de turismo de passeio pedestre em Portugal.

As regiões apresentam diferentes caraterísticas, em termos de recursos, condicionando o tipo de programas oferecidos. A maioria das regiões apresenta programas de 7/8 dias, com exceção do Centro e Lisboa, que figuram em programas de duração mais curta. Estas regiões são as mesmas que quase não figuram nos programas dos operadores estrangeiros. No entanto, são regiões que ocupam posições importantes quando se considera o número de quilómetros de percursos homologados e o número de atividades de pedestrianismo com a duração de um dia. Pode afirmar-se, mesmo antes de considerar outros fatores como, por exemplo, a existência de alojamento adequado, as acessibilidades ou outros serviços que, apesar do potencial que estas duas regiões oferecem para 
a prática do pedestrianismo, não estão a explorar esse valor, do ponto de vista turístico.

Abordando destinos mais específicos, destacam-se as áreas protegidas, em todas as regiões do país, o Douro, no Norte, e as Aldeias Históricas e Aldeias do Xisto, no Centro.

Estes três últimos, são destinos de montanha e/ou elevado valor natural, que se afirmam pela cuidada revitalização do património construído, para fins turísticos, e que integram interessantes elementos naturais, culturais e paisagísticos. Os percursos pedestres são assumidos como fator de inovação, parte integrante das recentes estratégias de desenvolvimento e componentes do produto turístico a desenvolver. Neste momento (meados de 2011) estão disponíveis 21 percursos ("Caminhos do Xisto"), repartidos por $160 \mathrm{~km}$, ligados a 20 das 27 aldeias que constituem a Rede de Aldeias do Xisto. A disponibilidade de informação detalhada sobre os percursos e serviços no destino, as adequadas infra-estruturas de acolhimento, sinalização e outros equipamentos (como, por exemplo, áreas de descanso, praias fluviais, centros de acolhimento e informação), e a variada oferta de percursos adaptada a diversos utilizadores, são fatores relevantes de diferenciação e de êxito deste destino.

\section{Conclusão}

A prática de andar a pé em trilhos sinalizados, ou pedestrianismo, é uma atividade que tem vindo a ganhar um número crescente de praticantes e que utiliza, como recurso fundamental, os percursos pedestres.

O crescente número de praticantes elevou a prática de um lazer informal a uma verdadeira ação turística, potencialmente geradora de benefícios a nível local.

Neste contexto, os percursos pedestres assumem importância como forma de complementar a experiência do turista num determinado destino, ao constituírem mais uma oferta de atividade em que o turista pode participar, mas também podem assumir o papel principal no produto turístico e constituírem a razão da deslocação ao destino. 
Portugal não é um país com forte tradição de pedestrianismo, contudo a atividade tem vindo a desenvolver-se. Existem mais de duas centenas e meia de percursos pedestres homologados, distribuídos pela totalidade do território nacional, com exceção do arquipélago dos Açores (onde existe uma importante oferta deste tipo de recurso, embora não homologados pela Federação de Campismo e Montanhismo de Portugal). Esta oferta de percursos pedestres homologados (repartidos por quase 3500 quilómetros) é maior em áreas de montanha e de elevado interesse natural (com estatutos de proteção nacional e internacional).

Por outro lado, foi possível identificar um importante conjunto de operadores, portugueses e estrangeiros, a oferecerem produtos de turismo de passeio pedestre em Portugal. Os programas apresentam-se em diferentes modalidades, em termos de duração e de configuração dos serviços incluídos.

Grande parte dos programas organizados por empresas portuguesas corresponde a programas de 1 dia, sendo escassa, em comparação com o que oferecem os operadores estrangeiros, a oferta de programas com duração superior a 4 dias, o que revela um subaproveitamento da oportunidade de oferecer programas de turismo de passeio pedestre estruturados.

Para todas as regiões de Portugal, existe oferta de programas de turismo de passeio pedestre. Esta oferta ocorre com maior frequência em áreas de grande interesse natural e em áreas de montanha.

Destacam-se as regiões Norte e Lisboa, quando se consideram os programas de 1 dia. A apreciação de programas com duração superior confere a importância da região Norte, e faz sobressair também as regiões da Madeira, Algarve, Alentejo e Centro, como principais destinos de turismo de passeio pedestre em Portugal.

A análise da expressão do turismo de passeio pedestre em Portugal, através do estudo da oferta, permite perceber que existe uma tipologia de território preferencial para o desenvolvimento deste tipo de produto turístico e que este pode constituir, nalguns casos, uma oportunidade de diversificação da base económica local. 


\section{Referências bibliográficas}

Bietolini, A. 2007, Manual de Caminhada - Trekking, Arte Plural Edições.

Butler, R., Hall, C. M. and Jenkins, J. (eds.) 1998, Tourism and Recreation in Rural Areas. Chichester: John Wiley \& Sons.

Calixto, V. e Dores, A. 2008, Guia de Percursos Pedestres (Algarve). Faro: Região de Turismo do Algarve e Comissão de Coordenação e Desenvolvimento Regional do Algarve.

CARvalho, P. 2009, "Planeamento, turismo e património em territórios de baixa densidade", Biblos, Vol. VII (2. ${ }^{\text {a }}$ série), pp. 485-506.

EG. 2009, "Trek \& Trail - L'outdoor garde le ritme”, Sport Première Magazine, Julho/Agosto de 2009, pp. 3-4.

Federação Portuguesa de Campismo. 2000, Pedestrianismo - O desporto dos que andam a pé. Percursos Pedestres - Normas para implantação e marcação, Federação Portuguesa de Campismo e Secretaria de Estado do Desporto, Portugal.

Godde, P., Price, M. \& Zimmermann, F. (eds.) 2000, Tourism and Development in Mountain Regions. New York and Oxon: Cabi Publishing.

Gonçalves, J. 2002, Passo-a-passo - Percursos Pedestres de Portugal, Federação Portuguesa de Campismo. Lisboa: Instituto Nacional do Desporto.

Hall, D., Roberts, L. and Mitchell, M. (eds.) 2003, New Directions in Rural Tourism. Aldershot: Ashgate.

HALl, C. M. and PAGE, S. J. 2006, The Geography of Tourism and Recreation. Environment, place and space. London and New York: Routdlege.

Kouchner, F. \& LYARD, J. 2001, "A valorização do turismo de passeio pedestre nos territórios rurais - Guia pedagógico para a elaboração e execução de um projecto de passeio pedestre", Inovação em Meio Rural, Caderno n. ${ }^{\circ}$ 12, Observatório Europeu Leader. Disponível em: http://ec.europa.eu/agriculture/rur/ leader2/rural-pt/biblio/walking/walking.pdf, último acesso em 12-02-2009).

Lopes, A. 2003, Percursos pedestres no Parque Natural do Vale do Guadiana. Contribuição para a sua implementação no âmbito do Turismo de Natureza. Évora: Universidade de Évora, Dissertação de Mestrado em Gestão de Recursos Biológicos.

MEI - Ministério da Economia e Inovação (2009), "Decreto-Lei n. 108/2009", Diário da República, $1 .^{a}$ série, N. ${ }^{\circ}$ 94, 15-5-2009, pp. 3035-3045. 
Ministério do Ambiente e Ordenamento do Território - Agência Portuguesa do Ambiente. 2010, Sistema Nacional de Informação Geográfica-Atlas do Ambiente. Disponível em: http://www2.apambiente.pt/atlas/est/index.jsp, último acesso em 28-1-2010.

PENT. 2007, "Plano Estratégico Nacional do Turismo", In Diário da República, 1. ${ }^{a}$ Série, n. ${ }^{\circ} 46,4.4 .2007$, pp. 2166-2174.

PeArCe, D. \& Butler, R. (eds.) 2005, Contemporary Issues in Tourism Development. London and New York: Routdlege.

PRICE, M. 2007, Mountain Area Research and Management. Integrated Approaches. London: Earthscan.

Redelif, M.; HAAN, H. \& KASINIS, B. (eds.) 1997, Sustainable rural development. Aldershot: Ashgate.

Região Autónoma dos Açores - Assembleia Legislativa Regional. 2004, "Decreto Legislativo Regional N. ${ }^{\circ}$ 16/2004/A”, Diário da República, I Série A, N. ${ }^{8}$, 10-4-2004, pp. 2221-2224.

Região Autónoma da Madeira - Assembleia Legislativa Regional. 2000, "Decreto

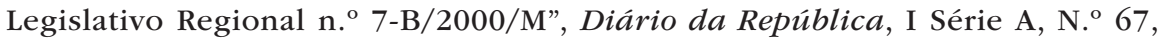
20-3-2000, pp. 1080(2)-1080(6).

Rodrigues, A. 2006. "Os trilhos pedestres como uma actividade de lazer, recreio e turismo - uma análise exploratória ao mercado dos trilhos pedestres em Portugal”, Revista Turismo \& Desenvolvimento, n. ${ }^{\circ}$ 6, pp. 83-94.

THR. 2006, Turismo de Natureza, Lisboa, Turismo de Portugal. Disponível em: http://www.turismodeportugal.pt/Portug\%C3\%AAs/Proturismo/ProdutoseDestinosturisticos/ProdutosTuristicos/TurismodeNatureza/Anexos/TURISMO\%20 De\%Natureza.pdf, último acesso em 16-02-2009).

Tovar, Z. 2010, Pedestrianismo, Percursos Pedestres e Turismo de Passeio Pedestre em Portugal, Dissertação de Mestrado em Turismo (Gestão Estratégica de Destinos Turísticos) apresentada à Escola Superior de Hotelaria e Turismo do Estoril. Vergunst, J., Árnason, A. and Shucksmith, M. (eds.) 2009, Comparing rural development. Continuity and change in the countryside of Western Europe. Aldershot: Ashgate. 